„Logopedia Silesiana”, t. 8, ISSN 2391-4297

DOI 10.31261/LOGOPEDIASILESIANA.2019.08.03

(cc) BY-SA

\author{
Светлана М. ВАЛявко \\ ИПССО ГАОУ ВО МГПУ \\ (D) 0000-0001-7195-6374
}

\title{
О поведенческом подходе в работе логопедов Исторический экскурс и современная ситуация в российской логопедии
}

\begin{abstract}
On Behaviourism in Speech Therapy: An Excursus on Russian Speech Therapy and Russian Logopaedia Today

Авsтract: The article discusses the influence of behaviorist theory on logopedic science. Describes the historical experience in the application of behavioral techniques speech therapy intervention and formation on its basis of individual plans of impact specialists and speech therapists. Such an excursion seems to be relevant in connection with the introduction of individual programs of correctional work into Russian education. The results of the author's study of the experience of using different types of reinforcements in the modern activities of speech therapists in Russia are discussed.

KeY wORDs: behaviorism, behavioral theory, conditioned reflex therapy, behavioral techniques, reinforcement, speech therapy, speech therapy intervention, Individualized Education Plans (IEPs), The Program of correctional work
\end{abstract}

\section{Бихевиоризм и его роль в американской психологии}

Для исследования столь сложного предмета, как человеческое поведение, совершенно необходимо наличие аргументированной теоретической базы. В силу недостаточности теоретических разработок, некоторые формы человеческого поведения в течение долгого времени не становились предметом научного изучения. Американская психология как самостоятельная наука начала развиваться позднее, чем европейская. Благодаря работам психологов во главе с У. Джемсом она привлекает к себе внимание мирового психологического сообщества, а позднее, с появлением работ К. Л. Моргана и Э. Торндайка, все больше определяет научную атмосферу психологии конца XIX и первой половины XX века. Господствующее положение в ней занял классический бихевиоризм Дж. Уотсона. Его представители считали, что научному изучению подлежат объекты непосредственного наблюдения. 
По их мнению, только этот путь был единственным для того, чтобы психология стала истинной наукой. Все феномены иного, невидимого плана, недоступные инструментальному оцениванию, не получают признания. Предметом психологии, таким образом, становится поведение, а не сознание (психика). В этом и заключалось кредо нового направления - бихевиоризма (от англ. Behavior - поведение). Девизом бихевиоризма, как отмечал М.Г. Ярошевский (1996), стало «понятие о поведении как объективно наблюдаемой системе реакций организма на внешние и внутренние стимулы» (с. 215). Это понимание зародилось в трудах русских ученых И.М. Сеченова, И.П. Павлова и В.М. Бехтерева, которые предложили инновационный путь изучения взаимодействия организма со средой с опорой на объективные методы. В этой связи особенно ценен научный вклад И.П. Павлова в становлении практики поведенческой терапии, учитывающей воздействие механизмов описанных им феноменов генерализации стимулов, различения стимулов и угасания условной реакции. Бихевиористы пошли дальше к девальвации и игнорированию влияния когнитивных функций, принципиальному предпочтению в изучении открытых, доступных непосредственному наблюдению действий и зависимости этих действий от этой среды, ее объективный детерминизм. Причем конгруэнтность поведения со средой осуществляется на вероятностной основе - идея, пришедшая позднее на смену классической оперантной обусловленности.

Выдающиеся работы Э. Толмена, К. Халла обогатили теорию бихевиоризма включением в сферу исследовательского интереса особых опосредующих процессов, названных посредниками («промежуточные переменные»), содержанием которых выступали уже сложные психологические образования. Внимание, мотивы, цели, различного рода отношения, представления и т. д. «встраивались» между стимулами и ответными реакциями, что позволило провести переоценку бихевиористической концепции Дж. Уотсона, смягчив тем самым серьезную критику бихевиоризма со стороны многочисленных его противников, в основном, в лице гештальтпсихологов и психоаналитиков (Романовой, Рыжова, Рябова, \& Кезиной, 2007).

Центральное место в теории бихевиоризма и необихевиоризма отводится работам Б.Ф. Скиннера, определившего главенствующую роль культуры как непосредственного фактора воздействия на поведение человека, что в дальнейшем рассматривалось им в контексте оперантного обусловливания. Учение об оперантном обусловливании позволило сформулировать тезис о принципиальной возможности контролируемого отстраивания человеческого поведения в заданных образцах - моделях (Романовой и др., 2007). А. Бандура, напротив, подчеркивал особое значение роли когнитивных факторов в формировании поведения человека, считая, что они участвуют в оценке сигналов, исходящих от других людей, и служат ориентиром для коррекции собственного повеления. В дальнейшем теоретические 
положения бихевиоризма нашли свое продолжение в теориях социального научения, социального бихевиоризма (А. Бандура, Дж. Роттер, Дж. Мид, Д. Доллард и т.д.) и др.

По мнению известного российского историка психологии М.Г. Ярошевского именно бихевиоризм определил «лицо» американской психологии прошлого столетия. Поведенческий подход как научно-обоснованный и доказавший свою практическую эффективность стал широко использоваться не только в психологии, но и в американской медицине (психотерапии), образовании и бизнесе (Романовой и др., 2007; Ярошевский, 1996; Klein \& Moses, 1999).

\section{Поведенческое направление в разных отраслях человеческого знания}

В психотерапии популярность поведенческого подхода способствовали как усиливающаяся неудовлетворенность психоанализом, как методом коррекционного воздействия, так и относительно быстрая и видимая положительная динамика поведенческого воздействия.

Современная психология и психотерапия, особенно детская, широко применяет поведенческие техники. Поведенческое направление представлено и в зарубежной, особенно американской, логопедии (speech therapy), которая базируется на поведенческой основе. Как отмечали Harriet B. Klein и Nelson Moses и др., бихевиоральная теория не была доминирующей парадигмой в коррекции речевой патологии до 1960-х годов (Hanson, 1983; Klein \& Moses, 1999). Как указывали авторы, в последние несколько десятилетий прошлого века существовало не менее пяти психологических теорий, которые оказали сильное влияние на модель логопедического вмешательства: психолингвистическая, когнитивная и пр. Однако обзор этих процессов влияния на профессиональную сферу логопедии справедливо начать с поведенческой теории, «потому, что хотя есть и другие примеры, он (бихевиоризм - C.В.) возможно больше, чем другие парадигмы, дал для переосмысления планирования вмешательства в случаях речевых недостатков» (Klein \& Moses, 1999, c. 46-47)1.

Практически во всей англоязычной логопедической литературе, доступной нам, до сих пор используются дефиниции бихевиоральных терминов или бихевиоральный тезаурус (Berry, 1980; Berry \& Eisensen, 1956; Hanson, 1983; Winitz, 1969). Надо подчеркнуть, что наряду с классическим поведен-

\footnotetext{
1 stright Перевод наш - S.B.
} 
ческим направлением (radical behaiviorism), в котором ребенок воспринимался как «чистый лист» от рождения, а далее как реагирующий организм и результат условного воздействия (Skinner, 1957), в современной американской и европейской науке становится все более популярным подход, менее жесткий и более эклектичный по своему характеру. Некоторые логопеды стали использовать в качестве основы и другие научные традиции, в частности, когнитивную теорию (Ferguson, 1978; Reid \& Hresko, 1981). Вместо элиминирования определенного поведения допускается, что ребенок имеет свои потребности и мотивы, а также особенности темперамента и личностного реагирования. С.Н. Шаховская (2001) в своем обзоре указала, что иностранные методисты «отмечают роль сознательности, самостоятельности и организованности ребенка» (с. 250), а «в ряде работ основной акцент смещается с метода логопедического воздействия на личность ребенка с нарушениями речи» (с. 251). Отметим, что в отечественной логопедии личностно-ориентированный подход имеет более давние традиции.

Современные программы изменения речевого поведения, которые базировались на общих бихевиоральных принципах обучения, все больше адаптируются к конкретному пациенту. В своем труде «Articulation» Marvin L. Hanson (1983) привел краткий обзор таких программ и сообщил данные об их эффективности. По его сведениям, использование принципов поведенческого подхода при нарушениях произношения дает положительный результат от 50 до 90\% случаев. Автором достаточно подробно описывается техника и стратегия изменения речевого поведения. От пациента не ожидается, что он сможет освоить определенный артикуляционный уклад (или желаемое речевое поведение) за один большой этап, это происходит пошагово. Каждый небольшой шаг селективно подкрепляется. Неподходящие реакции игнорируются либо лишаются поощрения. Нужные, ведущие к намеченной цели, вознаграждаются. Таким образом, логопед использовал как негативное, так и позитивное подкрепление. Каждый раз, когда пациент произносил звук точнее, ближе к эталонному звуку, чем раньше, он получал подкрепления, приятные для него. Постепенно артикуляционные движения пациента все больше и больше становились похожими на желаемый образец. Шаги, ведущие к желаемому поведению, а также вся процедура по его формированию называются успешным приближением. Логопеду важно обеспечить подкрепление каждого такого шага. Пациент не получает подкрепления, пока не продемонстрирует каждый следующий освоенный шаг речевого поведения. Соответственно, специалисту необходимо внимательно наблюдать за ним и фокусироваться на позитивном подкреплении.

Автор указывал, что в отношении подкреплений существуют определенные рекомендации. Подкрепление наиболее эффективно, когда оно следует немедленно за реакцией, т.е. подкрепляется каждая желательная реакция. С прогрессом логопедического воздействия положительные стимулы дают- 
ся через большие промежутки времени - это так называемое прерывистое подкрепление (Hanson, 1983).

Выделяют первичные (инициальные) подкрепления, которые связаны с такими биологическими потребностями, как пища и физический комфорт. Вторичные подкрепления представляют приобретенную систему ценностей (жетонов, знаков, оценочных символов). Их так и называют - символические подкрепления. С маленькими детьми предпочтительнее используют первичные подкрепители, по меньшей мере, в начале коррекции. Вторичные подкрепления считаются более сильными, они ускоряют логотерапевтический прогресс в большей степени.

Фактически способы и варианты использования данной стратегии ограничены только креативностью специалиста. Он вовлекает в процедуру коррекции родителей, сверстников, лиц ближайшего окружения. Сами подкрепители (вознаграждение) должны быть подобраны индивидуально, путем соответствующего отбора. Среди требований к их подбору - однозначность, т.е. положительный стимул должен восприниматься именно как положительный, адресованный лично. Его нельзя получить другим способом, он должен постоянно сохранять личностную значимость. Вознаграждение может быть не материальным, а поведенческим. Например, разрешение посмотреть мультфильм, возможность дополнительного внимания, социального взаимодействия и т.д. Это считается средствами, формирующими желаемое поведение ребенка, активизирующими его. Однако, как отмечает С.Н. Шаховская (2001), не все зарубежные методисты разделяют эту точку зрения, считая практику подкрепления в виде «поощрения - отсутствия поощрения» источником постоянного напряжения ребенка.

Другие авторы, подчеркивали значимость соииальных подкреплений. Например, Mildred Freburg Berry (1980) писала, что материальные награды со временем стали менее необходимыми в коррекционном процессе, а словесная похвала и одобрение людей вне круга значимых других (иногда подстроенное) становились эффективным подкреплением. Если же ребенок стал более успешным в устной речи, его достижения становились мотивирующей силой, т.е. самоподкреплением. Ребенок приобретает чувство самоценности, собственного достоинства, он осознает, что в силах контролировать свою речь и, что наиболее существенно, таким образом, он принимает на себя ответственность за свое собственное обучение. Следовательно, через генезис различных подкреплений можно, по мнению исследователей, выйти на внутреннюю мотивацию ребенка к коррекции его речевого дефекта. 


\section{Влияние поведенческого похода на методологию логопедического вмешательства}

Первый американский билль о правах лиц с ограниченными возможностями PL-94-142 был принят в 1975 г. Это закон требовал, чтобы для детей с недостатками развития, получающих субсидированные образовательные услуги на федеральном уровне, были разработаны индивидуальные учебные планы (Individualized Education Plans, далее по тексту IEPs). Врачи и педагоги, участники этого процесса, должны были конкретизировать цели вмешательства, процедуры и критерии для оценки достижения поставленных целей и задач (с указанием даты оценки). Индивидуальные учебные планы (IEPs), регламентирующие управление коррекционной работой, функционируют как официальный документ (Benner, 1992; Bigge, 1988; Cook, Tessier, \& Klein, 1992; Reid, Hresko, 1981).

Поскольку поведенческая психотерапия к этому времени была полностью оформленным самостоятельным научным направлением, и существовали успешные примеры прямого приложения поведенческой теории к практике в ряде отраслей (например, в финансовом менеджменте и т.д.), ее применили также в педагогике, в отношении формирования языковых компетенций. Так, в американской логопедии теория бихевиоризма оказала влияние на то, как IEPs были реализованы в соответствии с требованиями подотчетности закона PL-94-142 и последующего законодательства. Особенно она повлияла на формулирование целей коррекционного воздействия. Под влиянием поведенческой теории были сформулированы следующие принципы IEPs:

1. Цели воздействия должны быть написаны со ссылкой на выполнение функциональных задач (например, «чистка зубов», «говорить предложениями»).

2. При разработке образовательных целей задачи должны быть проанализированы и представлены как последовательность маленьких, управляемых навыков (эти навыки представляют собой восприятие шагов, необходимых для выполнения этой задачи.). В задаче следовало представлять один уровень цели; шаги, ведущие к достижению задач, являются вторым уровнем цели.

3. Цели должны быть записаны в терминах наблюдаемого поведения, а также должны быть определены критерии эффективности их достижения.

4. Постановка цели должна включать контекст, в котором вызывается определенное целевое поведение.

5. Принципы 1-4 применяются к формулировке целей, независимо от расстройства в стадии рассмотрения. 
Помимо влияния на формулирование цели, бихевиоризм, как теоретическая основа профессиональной деятельности, определял принципы, которые повлияли на планирование процесса логопедического воздействия. Эти принципы поставили врачей-логопедов перед осознанной необходимостью решения критической проблемы, каким образом дети овладевают языком. Основная поведенческая предпосылка этого важного вопроса состояла в том, что языковое поведение формируется процессуально и последствия этого формирования могут контролироваться через наблюдаемые события, реакции во внешней среде. Кроме того, действуют законы оперантного обуславливания (англ. Operant - образец поведения). Во-первых, «Закон упражнения» (англ. Law of exercise): повторение определенного поведения способствует тому, что это поведение будет в дальнейшем воспроизводиться с все более высокой вероятностью. Во-вторых, «Закон эффекта» (англ. Law of effect): паттерн поведения, получающий положительный результат (позитивное подкрепление) в будущем будет встречаться с более высокой вероятностью, и наоборот, если действие приводит к неприятным последствиям или отсутствию результата, будет проявляться реже и может совсем исчезнуть (Hayes \& Hayes, 1992; Skinner, 1957). Положительные результаты, которые увеличивают вероятность того, что поведение будет использоваться, снова являются подкреплениями. По Скиннеру эта закономерность называется «Законом выгоды» (англ. Law of profit). Так, логопед специально формирует «целевое» поведение, т.е. позитивно подкрепляет желательные поведенческие паттерны.

Для предупреждения субъективности и неопределенности американскими методологами были введены принципы планирования вмешательства, взятые из поведенческой теории. Это привело к пяти значительным изменениям в осмыслении и формулировании целей и выбора методов (методик) воздействия.

Во-первых, был сделан отход от ориентации на ненаблюдаемые процессы. Например, «различение звуков речи на слух» (цель, предложенная в классическом пособии M. Berry \& J. Eisensen) является внутренним процессом, т.е. ненаблюдаемым. Поэтому в поведенческих терминах эту цель нужно сформулировать следующим образом: «Джоан поднимет руку в ответ на слова, начинающиеся с «К», когда они произносятся в паре слов, начинающихся с «G» (Berry \& Eisensen, 1956).

Во-вторых, была предпринята попытка рассмотреть контекст, в котором ставилась цель воздействия. Цель, ставившаяся логопедами до «поведенческого» периода, не указывала условий ее реализации, т.е. этапа формирования навыка. Использование поведенческой терминологии просто предписывало делать это в обязательном порядке. Согласно Bigge (1988), цели, заявленные на весь период воздействия, и промежуточные цели курса (занятия) должны включать конкретные вещи, к примеру, наличие или 
отсутствие управления поведением и взаимодействие участников процесса, направленное на вызывание определенных поведенческих реакций (жестовые подсказки, словесные сигналы и т.п.).

B-третьих, произошло изменение в направлении дифференциации уровней целеполагания. В период этиологических категорий нет четкого различия между уровнями цели. В отличие от этого, в поведенческом подходе к планированию вмешательства различают краткосрочные и сеансовые уровни цели и простраивают связи между этими уровнями цели.

В-четвертых, бихевиоризм изменил мнение о технике последствий, направленных на формирование целевого поведения. В течение категориального периода планирование логопедического вмешательства не было обусловлено теориями обучения. Однако принципы, основанные на поведенческой (оперантной) теории, помогли в планировании усилий клиента.

И, наконец, в-пятых, поведенческое движение способствовало применению общего набора принципов планирования мероприятий для неясных клинических случаев. Эти принципы включают обучение наблюдаемым навыкам в конкретных условиях решения задач без учета типа расстройства.

Для того чтобы оценить важность «вливания» поведенческой психологии в логопедию, вспомним, что логопедия 40-х и 50-х годов прошлого века была сфокусирована на устранении симптомов, связанных с основными речевыми дефектами (Launer \& Lahey, 1981). Aram \& Nation (1982) назвали этот период “эрой этиологических типологий и дифференциальной диагностики» (с. 15). Этот период четко прослеживается и в российской логопедической науке (Лубовский \& Валявко, 2010).

Таким образом, поведенческий подход представляет собой переход от профессионального менталитета, характерного для категориальной (типологической) ориентации, к индивидуализации воздействия на отдельных лиц, принадлежащих к различным типам дизонтогенеза, но имеющих также свои индивидуальные особенности. Он планируется как воздействие специалиста на клиента. Кроме того, при этом прогнозируется формирующееся в ответ поведение клиента, т.е. их взаимодействие очерчивается в перспективе.

\section{Современная ситуация в российской логопедии (по данным опроса)}

Поскольку когнитивно-бихевиоральный подход в последние десятилетия стал активнее изучаться в российской психологии и психотерапии (Кузнецова, 2013; Федоров, 2002; Шевченко, 2003), нам представилось инте- 
ресным выяснить вопрос о применении сходных поведенческих техник в практической деятельности логопедов России. Известно, что методы, сходные с поведенческими, под названием условно-рефлекторной терапии использовались в Советском Союзе в разных областях, в том числе в логопедической, начиная с 20 -х годов прошлого века (Филичева, Орлова, \& Туманова, 2015). Модификации речевого поведения (по К-П. Беккер М. Совак «перевоспитанию поведения») уделялось определенное внимание, особенно при коррекции заикания (Беккер \& Совак, 1981), но специальных исследований данной проблемы практически не проводилось. Особенно актуальной она становится с оформлением такой области специальной психологии как логопсихология и реализацией личностно-ориентированного подхода в обучении и воспитании (Валявко, 2009b; Валявко \& Князев, 2014).

С целью выявления использования поведенческих подходов в российской логопедии в разработанные нами анкеты по мотивации дошкольников были включены вопросы, связанные с использованием подкреплений в логопедической практике (Валявко, 2009а). Опрос был проведен в 20062009 г.г. В нем участвовало 110 логопедов России (г.г. Москва, Красноярск, Краснодар). Респонденты отметили, что в своей практической работе постоянно используют «различные поощрения» (в контексте статьи - подкрепления) как социальные, так и материальные, а также подкрепление деятельностью, приятной для ребенка.

В качестве соииальных подкреплений наиболее часто применяется словесная похвала. Её в устной или письменной (графической) форме используют $72,7 \%$ логопедов. Значительно реже в 9,1\% случаев для этой цели применяются аплодисменты группы (организуемые логопедом), в 8,2\% - вербальное одобрение ребенка специалистом. Респонденты в 6,4\% случаев отмечали использование ими социально приемлемых элементов телесного контакта (поглаживание по голове, похлопывание по плечу). Публичная демонстрация своих успехов товарищам служит средством активизации в 4,5\% случаев. Возможность быть «командиром», «лидером», «солистом» (например, провести разминку, начать занятие, выбрать для всех игру, распределить в ней роли и т.п.) предоставлялась в 2,7\% случаев.

Для материального подкрепления чаще всего логопедами использовались «вкусные призы», такие как витамины, леденцы, драже, жевательные конфеты, крупяные подушечки, колечки и др. (ассортимент конкретного пищевого драйва был заранее согласован с родителями). Ими вознаграждают детей в случае успеха 20\% специалистов. В качестве других средств используются «подарки»: наклейки, картинки (27,3\%), небольшие игрушки, значки и пр. (27,3\%). Иногда учреждаются и переходящие призы: медали; специальные флажки; атрибуты, такие как «Мастер рассказа», «За лучший звук» - о них сообщили 3,6\% опрошенных. 
Различные виды деятельности также привлекались нашими респондентами в качестве позитивного поведенческого подкрепления. Это использовалось в 17,3\% анкетируемых специалистов. Чаще всего предлагалась продуктивная деятельность: рисование, закрашивание, лепка; в 14,5\% случаев это было удовлетворение личных просьб, возможность поиграть в интересные (новые) игры или игрушки (в том числе взять их из кабинета на время домой); некоторые малодоступные и привлекательные действия (игра на детском пианино и т.п.). Часть логопедов (10\% опрошенных) использовали универсальные подкрепители. В этой роли выступали символические заменители денег, жетоны, билетики разного цвета.

Подкрепления, которые применялись в работе с дошкольниками, резистентными к логопедическому воздействию, выявлялись отдельно. В качестве позитивных стимулов для детей данной группы использовались следующие: любимая или новая игровая деятельность (в 39,7\% случаев); устные побуждения, одобрение (24,8\% случаев); индивидуальные беседы и другие формы интереса к личности ребенка, в том числе индивидуальное дополнительное внимание; длительный зрительный контакт (19,8\%); нахождение личностно значимой для ребенка темы общения (17,8\%); похвала $(12,9 \%)$; демонстрация успешной деятельности другим детям (11,9\%). В единичных случаях анкетируемые специалисты занимались идентификацией подкреплений, выявляли их значимость для конкретного ребенка. На начальном этапе ими использовалась так называемая «приманка», т.е. предмет, обладающий для ребенка высокой привлекательностью, например, показ телефонного аппарата, коллекции и т.п. Чем младше ребенок, тем сильнее сказывается приоритет «реальных» поощрений над поощрениями социальными.

В бихевиоризме широко используется термин «наказание» - осуществление неприятных или нежелательных последствий в ответ на некорректное поведение (Бремс, 2002). Отметим, что отсутствие подкрепления в поведенческой терапии рассматривается как вид наказания. Выделяется также и «торможение нежелательного поведения» - нивелирование позитивных стимулов, присутствующих в окружении. Собственно говоря, педагоги не имеют права наказывать детей. Вопрос об использовании наказаний и аверсивного (отрицательного) подкрепления является очень деликатным и небезопасным для респондентов. На вопрос не ответило почти 50\% анкетируемых (50 чел.). 14 из 60 специалистов ответили, что они вообще не используют никакие ограничения в своей работе. Остальная часть респондентов назвала в качестве отрицательных подкреплений следующие: прекращение занятия с ребенком или временное отстранение его от занятий (26,9\%); введение правил, регламентирующих поведение и деятельность детей $(26,9 \%)$; замечания в спокойном тоне $(23,1 \%)$; запрет на игры после занятия (7,7\%); строгий взгляд, голос (7,7\%); лишение приза, поощрения (3,8\%). Отрицательные подкрепления, следовательно, сводятся на практике 
к отсутствию поощрения, лишению определенного положительного подкрепления и торможению для ослабления нежелательного поведения.

\section{Выводы}

Таким образом, практическая логопедия нуждается в применение техник, влияющих на поведение и успешность ребенка. Данные анализа материалов исследования позволяют сделать вывод о наличии элементов поведенческого подхода в практической деятельности логопедов российских дошкольных образовательных организаций. В принципе, российскими логопедами применяется множество видов подкреплений, хотя нельзя утверждать, что это происходит систематически и целенаправленно.

Это использование происходит, на наш взгляд, на наивно-эмпирическом уровне, т.е. вне профессионального целеполагания и технологий и потому не исчерпывает все возможности метода. Система подкреплений, используемых для формирования желательного речевого поведения, должна постепенно пересматриваться и варьироваться, изменяясь в зависимости от успехов ребенка. Знакомство с видами подкрепления может стать частью или самостоятельной технологией обучения навыкам работы или повышения уровня компетентности специалистов, актуальной на современном этапе работы с адаптированными образовательными программами (АООП) и специальными индивидуальными программами развития (СИПР).

Сегодняшняя ситуация в образовании ориентирована на удовлетворение индивидуальных потребностей детей. Каждый ребенок с речевыми недостатками имеет возможность получить индивидуализированную помощь, независимо от того, где он находится, в группе компенсирующей направленности или при интеграции в инклюзивное пространство. В настоящее время разработаны адаптивные образовательные программы для детей с нарушениями речи, в которых представлены направления деятельности логопеда и материалы для включения в программу коррекционной работы с такими детьми. Специалисты имеют возможность обогатить эти индивидуальные программы коррекционной работы новыми эффективными технологиями, ориентированными, в частности, и на зарубежные подходы. Одним из таких подходов является поведенческий, который можно использовать при реализации программы коррекционной работы. 


\section{Библиография}

Беккер, К-П., \& Совак, М. (1981). Логопедия. Москва: Медицина.

Бремс, К. (2002). Полное руководство по детской психотерапии (Ю. Брянцевой, пер.). Москва: Эксмо-Пресс.

Валявко, С.М. (2009а). Особенности мотивационной сферы старщих дошкольников с общим недоразвитием речи. Москва: Спутник-Плюс.

Валявко, С.М. (2009b). Почему дошкольники с общим недоразвитием речи резистентны к логопедическому воздействию? Дефектология, 2, 59-65.

Валявко, С.М., \& Князев, К.Е. (2014). Изучение потребностной сферы дошкольников с нарушениями речевого развития. Специальное образование, 2, 5-13.

Кузнецова, В.Б. (2013). Чувствительность к подкреплению как фактор психологического здоровья детей и подростков. Автореф. дис. ...канд. психол.н. Москва.

Лубовский, В.И., \& Валявко, С.М. (2010). Терминологические проблемы специальной психологии и специальной педагогики. Культурно-историческая психология, 1, 50-55.

Романовой, Е.С., Рыжова, Б.Н., Рябова, В.В., \& Кезиной, Л.П. (ред.). (2007). Энциклопедия истории психологии. Т. 3 (с. 327-473). Москва: Центр «Школьная книга».

Федоров, А.П. (2002). Когнитивно-поведенческая психотерапия. Санкт-Петербург: Питер.

Филичева, Т.Б., Орлова, О.С., \& Туманова, Т.В. (2015). Основы дошкольной логопедии. Москва: Эксмо.

Шаховская, С.Н. (2001). Методические поиски в зарубежной логопедии. В: Ю.Ф. Гаркуши (ред.), Ребенок. Раннее выявление отклонений в развитии речи и их преодоление. Москва: МПСИ - Воронеж, «МОДЭК».

Шевченко, Ю.С. (ред.). (2003). Бихевиорально-когнитивная психотерапия для детей и подростков. Санкт-Петербург: Речь.

Ярошевский, П.Г. (1996). История психологии от античности до середины ХХ в. Учеб. пособие. Москва: Академия.

Aram, D., \& Nation, J. (1982). Child Language Disorders. St. Louis: Mosby.

Benner, S. (1992). Assessing young children with special needs. White Plains, NY: Longman.

Berry, M. (1980). Teaching linguistically handicapped children. Englewood Cliffs: Prentice-Hall.

Berry, M., \& Eisensen, J. (1956). Speech disorders: Principles and practices of therapy. New York: Appleton-Century-Crofts.

BIGGE, J. (1988). Curriculum based instruction for special education students. Mountain View, CA: Mayfield.

CoOK, R.E., Tessier, A., \& Klein, M.D. (1992). Adapting early children curricula for children with special needs. New York: Merrill.

FERGUSON, C.A. (1978). Learning to pronounce: The earliest stages of phonological development in the child. In: F.D. Minifie, \& L.L. Lloyd (Eds.), Communicative and cognitive abilities: early behavioral assessment (pp. 237-297). Baltimore: University Park Press.

Hanson, M. (1983). Articulation. Philadelphia: Saunders.

Hayes, S.C., \& Hayes, L.J. (1992). Verbal relations and the evolution of behavior analysis. American Psychologist, 47, 1383-1395.

Klein, H., \& Moses, N. (1999). Intervention planning for children with communication disorders. A Guide for Clinical Practicum and Professional Practice. Boston: Allyn \& Bacon.

Launer, P., \& Lahey, M. (1981). Passages: From the 50s to the 80s in language assessment. Topics in Language Disorders, 1, 11- 29. 
Reid, D.K., \& Hresko, W.P. (1981). A cognitive approach to learn disabilities. New York: McGraw-Hill.

Skinner, B.F. (1957). Verbal behavior. New York: Appleton-Century-Crofts.

Winitz, H. (1969). Articulatory acquisition and Behavior. New York: Appleton-Century-Crofts Educational Division. Meredith Corporation. 